\title{
The Prevalence of Hypertension among Undergraduate Students in Basra City
}

\author{
Abdulkareem Ali Qassim ${ }^{1}$, Kadhim Almadwah ${ }^{2}$, Afkar F. Kareem $^{3}$, Muhammad Kairalla Madi ${ }^{4}$, Ali Sabah A.Alzahraa ${ }^{5}$
}

University of Basra/College of Nursing Basra, Iraq

DOI: $10.36347 /$ sjams.2020.v08i06.019

| Received: 12.05.2020 | Accepted: 02.06.2020 | Published: 20.06.2020

*Corresponding author: Abdulkareem Ali Qassim

Introduction: Birth asphyxia is one of the common cause of mortality and morbidity in neonate and the incidence is 2 9 per 1000 live born. Perinatal asphyxia is an important cause of mortality and of subsequent neurologic disabilities among the infants who survive. Aim \& objective: To study the incidence of mortality \& morbidity in birth asphyxia. Material \& Method: The study was conducted in the Obstetrics department, Special Newborn Care Unit (SNCU)/Pediatrics, District Early Intervention Centre (DEIC), department of SVP PG I P \& S C B Medical College, Cuttack after obtaining clearance from institutional ethical committee. The study was conducted from January 2018 to December 2019. The study was a prospective study. Result: Severe HIE (stage-III) was associated with a grave prognosis. Mortality was very high. Survivors had gross developmental delay and severe neurological deficits. Poor growth pattern was noted in HIE - II and HIE-III. Conclusion: Perintal asphyxia is preventable condition. Timely and corrective step taken during the each and every step during the delivery process will definitely reduce the incidence of perinatal asphyxia \& there by reducing the number of encephalopathy, also reduces the burdens of mortality and morbidity.

Keywords: Perinatal asphyxia, Neurological outcome, Hypoxic-Ischemic Encephalopathy, Neonatal mortality.

Copyright @ 2020: This is an open-access article distributed under the terms of the Creative Commons Attribution license which permits unrestricted use, distribution, and reproduction in any medium for non-commercial use (NonCommercial, or CC-BY-NC) provided the original author and source are credited.

\section{INTRODUCTION}

High blood pressure (hypertension) is a common health problem and a global public health challenge. Hypertension is a silent, invisible killer that can have few symptoms or warning signs. Globally, about one billion people have hypertension with twothirds of cases occurring in developing countries.

Hypertension is a major cause of premature death. The burden of hypertension is increasing and it is projected that by 2025 about 1.5 million people annually in the South-East Asia (SEA) Region will be diagnosed with hypertension [8]. Hypertension has been appointed as the greatest risk factor for early morbidity and mortality caused by Cardiovascular Diseases (CD). Framingham's studies show that increased blood pressure (BP) is associated to higher incidence of CD, which are an important problem for public health and is the main cause of death in most countries' adult population [1].

According to reports from the World Health Organization, chronic non-communicable diseases are the leading causes of death worldwide [2].
Data from the VII Joint National Committee on Prevention, Detection, Evaluation and Treatment of High Blood Pressure indicate that hypertension affects approximately 50 million people in the Unites States of America, and about 1 billion worldwide [4].

Cardiovascular diseases, particularly hypertension, account for high mortality in the form of coronary heart disease (CHD) in western countries and stroke in countries like India, Taiwan and Japan[5].

Prevalence of pre-hypertension among adults in the United States was approximately $31 \%$ and higher among men $(39 \%)$ than women $(23 \%)$. Prevalence of prehypertension and hypertension were significantly greater in South and West India as compared to Northern and Eastern India [6].

Data from the World Health Organization (WHO, 1997) indicate that they were the cause of about $30 \%$ of all deaths in the world, which corresponds to almost 15 million deaths each year, the majority (9 million) in developing countries. These data rank CD as a pandemic, whose treatment requires the adoption of effective primary and secondary preventive measures [7]. 


\section{Importance of the study}

Hypertension (HT) alone caused more than 7 million deaths worldwide in 2010. Hence it has become a serious health problem everywhere, not only because of its prevalence, affecting up to one third of world population, hypertension might start very early in life and their and modification could help in future prevention of these events discovery. Studies have shown that essential hypertension can be found among children and adolescents [3].

Statement: Prevalence of hypertension among undergraduate student (colleges' students) in Basra city

\section{OBJECTIVES}

(1)To investigate the prevalence of hypertension among students of colleges

(2)To investigate risk factors of hypertension among undergraduate students

\section{CHAPTER TWO}

\section{REVIEW OF LITERATURE \\ Definition of blood pressure}

It is the force of blood pushing against the walls of the arteries that carry blood from your heart to other parts of your body. Blood pressure normally rises and falls throughout the day, but it can damage your heart and cause health problems if it stays high for a long time. High blood pressure is also called hypertension [11].

\section{Definition of Hypertension}

Is a chronic condition in which arterial blood pressure is high? This height requires the heart to work harder than usual to be able to pump blood into the blood vessels. Blood pressure consists of two numbers: systolic pressure and diastolic pressure. This depends on the pressure exerted and measured during contraction of the heart muscle (contraction) or relaxation between the blows (extinction). Normal systolic blood pressure is between $100-140 \mathrm{mmHg}$ (upper reading) and diastolic between $60-90 \mathrm{mmHg}$ (lowexcessive if it is more than or equal to $140 / 90 \mathrm{~mm}$ $\mathrm{Hg}$ [10]. Hypertension is classified as primary (primary) hypertension or secondary hypertension. About 90-95\% of cases are classified as "basic hypertension", which means high blood pressure without a clear medical condition causing it[20].

\section{Medical Definition of hypertension}

Abnormally high arterial blood pressure that is usually indicated by an adult systolic blood pressure of $140 \mathrm{~mm} \mathrm{Hg}$ or greater or a diastolic blood pressure of $90 \mathrm{~mm} \mathrm{Hg}$ or greater [12]

\section{Signs \& symptoms of hypertension}

A person with hypertension may not notice any symptoms, and it is often called the "silent killer
[13]. Is chiefly of unknown cause but may be attributable to a preexisting condition (as a renal or endocrine disorder), that typically results in a thickening and inelasticity of arterial walls and hypertrophy of the left heart ventricle, and that is a risk factor for err reading). Blood pressure is in Basra city.

Various pathological conditions or events (as heart attack, heart failure, stroke, end-stage renal disease, or retinal hemorrhage)

A systemic condition resulting from hypertension that is either symptomless or is accompanied especially by:-

1-Dizziness

2- Palpitations

3- Fainting

4- Headache (12)

5-Nosebleeds [13]

Since humans are completely unaware of excessive blood pressure, it is only through measurements that it becomes detected. The exception is malignant.

Hypertension, which can cause headache, congestive heart failure, stroke, seizure, papilledema, renal failure and anuria [14]

\section{Diagnosis}

The hypertension diagnosis is basically established by permanently high tensional levels, that is, above normal limits, when BP is determined through appropriate methods and conditions. Thus, $\mathrm{BP}$ is a key element in the establishment of the hypertension diagnosis. In Brazil, its measurement is a mandatory procedure that should be performed by physicians of all specialties and other properly trained health professionals, in every clinical evaluation of patients of both genders [15].

\section{Risk factors}

Regarding risk factors for the hypertensive disease, these can be classified in constitutional, age, gender, genetic (race and family history) and environmental factors, including excessive consumption of salt, alcohol and fat in addition to smoking, and social status linked to work and social class[16].

Lifestyle factors such as cigarette smoking also contribute to hypertensive effects, mainly by stimulating the sympathetic nervous system. Smoking reduces artery flexibility and increases wave reflection to affect central blood pressure. Thus, hypertensive smokers are more likely to develop severe forms of hypertension [9]. "While undetected, it can cause damage to the cardiovascular system and internal organs, such as the kidneys. 
Regularly checking your blood pressure is vital, as there will usually be no symptoms to make you aware of the condition. It is maintained that high blood pressure causes sweating, anxiety, sleeping problems, and blushing. However, in most cases, there will be all. If blood pressure reaches the level of a hypertensive crisis, a person may experience headaches and there are usually no symptoms or signs of hypertension, and thus it is called the "silent killer".

\section{*Treatment and management}

While blood pressure is best regulated through the diet before it reaches the stage of hypertension, there is a range of treatment options. Lifestyle adjustments are the standard first-line treatment for hypertension.

\section{Regular physical exercise}

Doctors recommend that patients with hypertension engage in 30 minutes of moderateintensity, dynamic, aerobic exercise. This can include walking, jogging, cycling, or swimming on 5 to 7 days of the week.

\section{Stress reduction}

Avoiding stress, or developing strategies for managing unavoidable stress, can help with blood pressure control. Using alcohol, drugs, smoking, and unhealthy eating to cope with stress will add to hypertensive problems. These should be avoided.

Smoking can raise blood pressure. Giving up smoking reduces the risk of hypertension, heart conditions, and other health issues.

\section{Medications}

People with blood pressure higher than 130 over 80 may use medication to treat hypertension. Drugs are usually started one at a time at a low dose. Side effects associated with antihypertensive drugs are usually minor.

Eventually, a combination of at least two antihypertensive drugs is usually required. A range of drug types are available to help lower blood pressure, including: Diuretics, including thiazides, chlorthalidone, and indapamide. Beta blockers and alpha-blockers

- Calcium-channel blockers

- Central agonists

- Peripheral adrenergic inhibitor

- Vasodilators

- Angiotensin-converting enzyme (ACE) inhibitors

- Angiotensin receptor blockers

- The choice of drug depends on the individual and any other conditions they may have.

- Maintaining a healthy weight

- Getting enough physical activity

- Not smoking

- Limiting alcohol use

\section{- Healthy Diet}

Choosing healthful meal and snack options can help you avoid high blood pressure and its complications. Be sure to eat plenty of fresh fruits and vegetables.

Eating foods low in salt (sodium) and high in potassium can lower your blood pressure. The DASH (Dietary Approaches to Stop Hypertension) eating plan External is one healthy diet that is proven to help people lower their blood pressure [1].

For more information on healthy diet and nutrition, see CDC's Nutrition, Physical Activity, and Obesity Program Web site.

\section{Physical Activity}

Physical activity can help you maintain a healthy weight and lower your blood pressure. For adults, the Surgeon General recommends 2 hours and 30 minutes of moderate-intensity exercise, like brisk walking or bicycling, every week. Children and adolescents should get 1 hour of physical activity every day. For more information, see CDC's Division of Nutrition, Physical Activity, and Obesity Web site.

\section{No Smoking}

Cigarette smoking raises your blood pressure and puts you at higher risk for heart attack and stroke. If you do not smoke, do not start. If you do smoke, quitting will lower your risk for heart disease. Your doctor can suggest ways to help you quit.

\section{Limited Alcohol}

Avoid drinking too much alcohol, which can raise your blood pressure. Men should have no more than 2 drinks per day, and women only [19].

\section{Methodology}

Design of the study: A descriptive design was carried out to:-

(1)To investigate the prevalence of hypertension among student of colleges

(2)To investigate the risk factors of hypertension among undergraduate students in Basra city

Setting of the study: The study was conducted at Basra University Colleges for the period of November $1^{\text {st }} 2018$ to April $1^{\text {st }} 2019$.

Sample: The study sample was 500 males and females (18_25) years of age

\section{Study instruments}

(1) Questionnaire was designed and constructed for the purpose 1 the study of was consisted of 2 parts:

Part one. Demographic data sheet included the demographic character eristic; age; gender 
Part two. Questions related to hypertension disease.

(2)Sphygmomanometer

(3)Stethoscope

\section{Data Collection Methods}

Data collection through structured interview with the students and by using of the questionnaire. Data collection was initiated from Decamper $1^{\text {st }} 2018$ to March 152019 at Basra university colleges in Bab ALzubair and Germa.

\section{Statistical Data Analysis}

Data wear analyzed through the application of the following.

1: Descriptive data analysis:

Frequency

Percentage $-\%=$ F/sample $* 100 \%$

2- Mean

3- Standard deviation

4- Pearson correlation

5- Probability $\mathrm{P}(X)=\mathrm{N}(\mathrm{x}) /$ sample size

\section{CHAPTER FOUR}

\section{RESULTS AND DiSCUSSION}

Table-1: Distribution of sample according to the demographic; gender

\begin{tabular}{|c|c|c|}
\hline Gender & Frequency & Percentage \% \\
\hline Male & 230 & 46 \\
\hline Female & 270 & 54 \\
\hline Total & 500 & 100 \\
\hline
\end{tabular}

The majority of sample represents female 54\%

Table-2: Distribution of sample with hypertension disease

\begin{tabular}{|c|c|c|c|}
\hline $\begin{array}{c}\text { Total } \\
\text { sample }\end{array}$ & Frequency & Percentage\% & Probability \\
\hline 500 & 6 & 1.2 & 0.012 \\
\hline
\end{tabular}

Very rare cases among sample $(n=500)$
Table-3: Distribution of the hypertensive samples according to their age

\begin{tabular}{|c|c|c|}
\hline Age & Frequency & Percentage\% \\
\hline 19 & 1 & 16.7 \\
\hline 21 & 1 & 16.7 \\
\hline 22 & 1 & 16.7 \\
\hline 23 & 2 & 33.3 \\
\hline 25 & 1 & 16.7 \\
\hline Total & 6 & 100 \\
\hline
\end{tabular}

Nearly, all ages of sample (19-25) years are prone to hypertension disease.

Table-4: Distribution of hypertensive samples according to; gender

\begin{tabular}{|c|c|c|}
\hline Sample & Frequency & Percentage\% \\
\hline Male & 5 & 83.3 \\
\hline Female & 1 & 16.7 \\
\hline Total & 6 & 100 \\
\hline & & \\
\hline
\end{tabular}

The majority of hypertensive represents males and the minority represents females.

Table-5: Distribution of items (questions) and their percentage

\begin{tabular}{|c|c|c|c|c|}
\hline Questions & Yes & \% & No & $\%$ \\
\hline Q1 & 5 & 83.3 & 1 & 16.7 \\
\hline Q2 & 1 & 16.7 & 5 & 83.3 \\
\hline Q3 & 3 & 50 & 3 & 50 \\
\hline Q4 & 6 & 100 & 0 & 0 \\
\hline Q5 & 4 & 66.7 & 2 & 33.3 \\
\hline Q6 & 2 & 33.3 & 4 & 66.7 \\
\hline Q7 & 3 & 50 & 3 & 50 \\
\hline Q8 & 6 & 100 & 0 & 0 \\
\hline Q9 & 5 & 83.3 & 1 & 16.7 \\
\hline Q10 & 0 & 0 & 6 & 100 \\
\hline
\end{tabular}

The majority of risk factors represent both Q4\&Q8 (100\%) while the minority represents Q10 $(0 \%)$.

Table-6: Correlations (the relationship) between age $\&$ hypertension.

\begin{tabular}{|c|c|c|c|c|}
\hline Variable & BPs & BPd & $\begin{array}{c}\text { Mean } \pm \\
\text { Std.Deviation }\end{array}$ & Result \\
\hline Age Pearson correlation & 0.434 & 0.110 & $22.17 \pm 2.041$ & \\
P- value & 0.390 & 0.836 & $146.67 \pm 7.528$ & Insignificant \\
N & 6 & 6 & $90.00 \pm 8.944$ & \\
\hline
\end{tabular}

The result shows insignificant relationship between age and hypertension about personal correlation test $(\mathrm{P} \geq 0.05)$.

\section{DiscuSSION}

Table 1: This table shows that females have the highest number of males and their percentage of females $(54 \%)$. Table 2: Represents very rare case among sample $(n=500)$. A study was conducted in Angola during 2008; the prevalence of hypertension among age (18-29) was $(61.3 \%)$ of total sample (667) patient [21].

Table 3: Sample (18-25) this table reveals that nearly all ages of sample are exposed to hypertension. Table 4: This table reveals that the majority of hypertensive represents males $(83.3 \%)$. That means males are more prone to hypertension than females.

Table 5: This table shows that the major risk factors of hypertension among (18-25) years are items 4 
\& $8(100 \%)$. That means salt food and stress are the common causes (risk factors) of hypertension disease.

Table 6: This table shows insignificant relationship between age and hypertension disease $(\mathrm{P} \geq$ 0.05). That means there is no relationship between hypertension disease (systolic and diastolic) and age, i.e. all ages are exposed to hypertension.

A study was conducted in Iraq/Basra during 2010; there was no significant relationship between hypertension and age [2].

\begin{tabular}{|c|l|}
\multicolumn{2}{|c|}{ Symbols } \\
\hline No. of Question & \multicolumn{1}{c|}{ Definition } \\
\hline $\mathbf{1}$ & Is there any family history of hypertension? \\
\hline $\mathbf{2}$ & Are you smoker? \\
\hline $\mathbf{3}$ & Do you practice sport? \\
\hline $\mathbf{4}$ & Do you eat more salty food? \\
\hline $\mathbf{5}$ & Do you take more fats in your food? \\
\hline $\mathbf{6}$ & Do you take such drugs? If yes, what are they? \\
\hline $\mathbf{7}$ & Do you sleep adequately (8 hours daily)? \\
\hline $\mathbf{8}$ & Do you expose to tension (stress) much more? \\
\hline $\mathbf{9}$ & Are you nervous mood? \\
\hline $\mathbf{1 0}$ & Are you diabetic? \\
\hline
\end{tabular}

\section{Conclusion}

According to results, it has concluded that the prevalence of H.T. among students of ages (18-25) is very rare.

\section{RECOMMENDATION}

The study recommended that more studies should be conducted on large samples to investigate and control hypertension disease $\&$ its prevalence among students.

\section{REFERENCES}

1. Vasan RS, Larson MG, Leip EP, Evans JC, O'Donnell CJ, Kannel WB, Levy D. Impact of high-normal blood pressure on the risk of cardiovascular disease. New England journal of medicine. 2001 Nov 1;345(18):1291-7.

2. Ghadhban AH, Habib OS. A study on the distribution of blood pressure measurements among university students. The Medical Journal of Basrah University. 2011;29(1\&2):43-50.

3. De Lubango AN. La hipertensión arterial entre universitarios de la ciudad de lubango, angola. Rev Latino-am Enfermagem. 2008 Jul;16(4).

4. Wijayathunge LA, Hettiaratchi UP. Assessment of knowledge and risk factors of hypertension among school teachers in a selected district in North Central Province of Sri Lanka.

5. World Health Organization. World health statistics annual. World Health Organization; 1987.

6. SIngh RB, Fedacko J, Pella D, Macejova Z, Ghosh S, De AK, Begom R, Tumbi ZA, Memuna H, Vajpeyee SK, De Meester F. Prevalence and risk factors for prehypertension and hypertension in five Indian cities. Acta cardiologica. 2011 Feb 1;66(1):29-37.

7. Brando AP. Treating high blood pressure, reducing the risk of cardiovascular disease-Adult INSIGHT Study. Rev Bras Cardio. 2000; 2(5): 180-3.
8. Seedat YK, Rayner BL. South African hypertension guideline 2011. SAMJ: South African Medical Journal. 2012 Jan;102(1):60-83.

9. Virdis A, Giannarelli C, Fritsch Neves M, Taddei S, Ghiadoni L. Cigarette smoking and hypertension. Current pharmaceutical design. 2010 Aug 1;16(23):2518-25.

10. Supplier Dictionary, Baalbaki, Beirut, Lebanon.

11. High Blood Pressure Fact Sheet". CDC. 19 February 2015. Archived from the original on 6 March 2016. Retrieved 6 March 2016.

12. Merriam-webster.com/dictionary/hypertension

13. Medicalnewstoday.com/articles/150109.php.2013

14. Baker K. Hypertension \& its Pharmacological Management. Health Sciences and Technology. 2005;151:3-4.

15. Brazilian Society of Hypertension. Brazilian Society of Cardiology. Brazilian Society of Nephrology. IV Brazilian Guidelines on Arterial Hypertension. Campos do Jordão (SP): SBH / SBC / SBN; 2002

16. Ministry of Health (BR). Department of Health Programs. Coordination of Cardiovascular Diseases. Control of arterial hypertension: a proposal of teaching-service integration. Rio de Janeiro (RJ): Ministry of Health; 1993

17. Medicalnewstoday.com/articles/150109.php2013

18. National Heart, Lung, and Blood Institute. You're Guide to Lowering Your Blood Pressure with DASH. NIH Pub No 06-4082. Bethesda, MD: National Heart, Lung, and Blood Institute; 2006.

19. Carretero OA, Oparil S. Essential hypertension: part I: definition and etiology. Circulation. 2000 Jan 25;101(3):329-35.

20. Hayashida M, Santos CB, Cesarino EJ, Nogueira MS. Rev Latino-am Enfermagem julho-agosto. 2008; 16(4):672-8. 